Meta

Journal des traducteurs

Translators' Journal

\title{
Lexical and Discoursal Problems in English-Arabic Translation
}

\section{Mohammed Farghal}

Volume 40, numéro 1, mars 1995

URI : https://id.erudit.org/iderudit/002722ar

DOI : https://doi.org/10.7202/002722ar

Aller au sommaire du numéro

Éditeur(s)

Les Presses de l'Université de Montréal

ISSN

0026-0452 (imprimé)

1492-1421 (numérique)

Découvrir la revue

Citer cet article

Farghal, M. (1995). Lexical and Discoursal Problems in English-Arabic Translation. Meta, 40(1), 54-61. https://doi.org/10.7202/002722ar
Résumé de l'article

À partir de l'étude des résultats d'un examen de traduction, l'auteur examine cinq problèmes, lexicaux et/ou discursifs, dans la traduction anglais-arabe. Il démontre qu'un traducteur professionnel doit prendre un grand nombre de décisions afin de produire un équivalent traductionnel et que celles-ci sont souvent ignorées par les apprentis traducteurs qui, en général, se limitent à leurs dictionnaires pour trouver des solutions. 


\title{
LEXICAL AND DISCOURSAL PROBLEMS IN ENGLISH-ARABIC TRANSLATION
}

MOHAMMED FARGHAL

Yormouk U/niversity, Irhid, Jordun

\begin{abstract}
Résumé
A partir de l'étude des résultats d'un examen de rradurtion. lauteur examine cing problèmes, lévicaux êlou discursifs, dans la traduction anglais-arabe. II démontre qu' un traducteur professionnel doit prendre un grand nombre de décisions afin de produire un equivalent traductionnel et que celles-ci somt sonent ignorie's par less apprentis traducteurs qui en général. se limitent do leurs dictionnaires pour trouter des solutions.
\end{abstract}

\section{INTRODUCTION}

Translation is generally viewed as the process of establishing equivalence between the source language (SL) and the target language (TL) texts. The translator's task is therefore to establish translation equivalence (TE), thus explicitly or implicitly aiming for the actualization of the equivalent effect principle. that is, the TL text should have effects on the TL audience comparable to those brought about by the SL text on its original audience. This, however, remains a desirability rather than an entailment, for the equivalent effect fluctuates depending mainly on the text-type, i.c., whether it be informative, vocative or creative/expressive, and the closeness or remoteness of the SL to the TL culture. This being so, differing translation techniques are called for such as literal vs. free translation and semantic vs. communicative translation (Newmark 1981; 1988). The deficit/nonequivalence phenomenon is by no means confined to translation; it is rather a problem of communication at large. Thus neither total translation nor total communication is possible (Garcia-Landa 1990: 478).

In the heat of searching for TE, translation theorists have variously focused on translation as a product or as a process. Bolinger (1966: 130) defines translation generally as "The rendition of a text from one language 10 another." Similarly. Catford (1965: 20), looking at translation in terms of formal/grammatical equivalence, defines it as "The replacement of textual material in one language (SL) by equivalent textual material in another language (TL)." In this static view, the translator should look for formal correspondences from the micro-level, i.e.. grammatical units, to the macro-level, i.e., the text in its entirety.

Some theorists, on the other hand, talk about translation dynamically rather than statically, thus viewing it as a process that brings the message rather than the form to the fore. Jakobson (1959: 23.5) looks at translation in terms of substituting messages in one language for messages in another language. Similarly. Nida $(1964 ; 1969 ; 1977)$ talks about the reproduction of the SL message by the closest natural equivalent in the TL, thus bringing about dynamic equivalence or functional equivalence (de Waard and Nida 1986) in translating. Consequently. what is preserved in translating is the message rather than the form, for it is the message that the participants keep consulting at every phase in the process of communication.

The tug-of-war belween formal and dynamic equivalence seems endless. However, there remains the hometruth that one-to-one surface structure correspondence, as advo- 
cated by Catford (1965), is virtually non-existent nor is the one-to-one deep structure congruence (Krzeszowski 1971). In spite of this, what can be said in one language can be said equally well in another language (Kachru 1984: 84). In this spirit, formal equivalence should be looked at as one-to-many rather than one-to-one correspondence and/or congruence. Consequently, equivalence, whether it be formal or dynamic, should be viewed as a matter of relational dynamics in a communicative act - it is realized in that act and has no separate existence outside it (Ivir 1981: 53). That is to say, an SL text, message-wise, can be expressed via differing realizates in the TL. and so is it, form-wise. due to the existence of one-to-many correspondences. This state of affairs is analogous to the abstract status held by a phoneme in relation to its allophones. Contrastive linguistics, therefore, should take as points of departure some areas of meaning, e.g. causativization (Kachru 1984), evaluativeness (Farghal 1991), etc.

More interestingly, Lotfipour-Saedi (1990) develops a discourse-based model that intends to bring about translation equivalence. His model hinges on seven discoursal factors, namely, vocabulary, structure, texture, sentence meaning vs. utterance meaning, language varieties, aesthetic effect and cognitive effect. He asserts that TE should be characterized in terms of a negotiatory interaction of all these factors, for these factors interact with one another for the materialization of the communicative value of a text and the surface text acts as the embodiment of this interactive process. It should be noted that some of these factors may become far more important than others depending on text-type, e.g. the aesthetic effect is relevant only to the translating of serious literature. Lotfipour-Saedi stresses the interactive nalure of these factors, writing (p. 390), " $\mid . .$.$] it should be emphasized again$ that these conditions do not act in isolation from one another; but they rather interact with one another for establishing the TE. For example, what may be considered as a TE of an SL vocabulary element in isolation from the other six conditions may tum out to be a completely defective TE in relation to them." We will have occasion to touch on the role of some of these factors in bringing about TE when we discuss the empirical data in this paper.

\section{THE PRESENT STUDY}

This study aims to look into five lexical and/or discoursal problems encountered by advanced translation Arab students in English-Arabic translation. The data derive from the English-Arabic translation task on the comprehensive examination for the MA translation students in the Language Center at Yarmouk University. The examinees, numbering 15, had already completed at least two years of translation training. both practical and theoretical, before they sat for the test in May, 1991. It can be fairly assumed that the examinees have put optimal effort in the relevant translation task because of its being an integral part of their degree requirements. The examinees were allowed to freely use all types of reference books during the on-sight examination.

Following is the English text taken from a post-Gulf war issue of "The Time." The study items are in boldtype.

Baby Sieps for Peace

There will be no Hail Mary passes in this round of the Arab-Israeli peace search. As he completed his trip to the Middle East last week, Secretary of State James Baker argued for incremental progress, not a big, bold plan. "You have to crawl before you walk, and you have to walk before you run", he said in Damascus. Baker didn't lean on anyone during this visit. $|0|$ The pressure will begin gently this week with Baker's follow-up phone calls to the leaders he saw, then intensify when President Bush makes his own trip to the region, expected later this spring. Bush aides say... 


\section{ANALYSIS AND DISCUSSION}

The first study item Hail Mary passes is a Christian metaphorical expression alien to the Arab/Muslim culture. The linguistic representation of experience frequently differs from one language and/or culture to another. Dagut (1981:63) writes, "It is through words that human beings, as speakers of language. classify and represent their experience, whether this takes the form of external sensory impressions or inner emotions and thoughts." This representation, of which metaphors are a key component, is basically selective. Consequently, metaphors rarely correspond formally and/or functionally across languages. This creates situations where a metaphor should be reduced to its communicative import in the process of translating. Being encountered in a journalistic material, the aforementioned metaphor was expected to be reduced to its communicative sense by the examinees, thus be treated as a decorative rather than a creative metaphor (Broeck 1981: 76). Unfortunately, however, only four of them managed to do so successfully. Their renderings are listed in (1) below.

\begin{tabular}{|c|c|c|c|c|c|}
\hline $\begin{array}{l}\text { (1) a. marham } \\
\text { ointment }\end{array}$ & $\begin{array}{l}-14 n \\
- \text { nom }\end{array}$ & $\begin{array}{l}\text { xiff } \\
\text { curing }\end{array}$ & $\begin{array}{l}-i n \\
-\operatorname{gen}\end{array}$ & & \\
\hline \multicolumn{6}{|c|}{ "An effective medicine" } \\
\hline $\begin{array}{l}\text { b. duriò } \\
\text { ways }\end{array}$ & $\begin{array}{l}-11 n \\
-n o m\end{array}$ & $\begin{array}{l}\text { mumahodat } \\
\text { paved }\end{array}$ & $\begin{array}{l}-14 n \\
- \text { nom }\end{array}$ & & \\
\hline \multicolumn{6}{|l|}{ "Paved ways" } \\
\hline $\begin{array}{l}\text { c. najäh } \\
\text { success }\end{array}$ & $\begin{array}{l}-l u n \\
- \text { nom }\end{array}$ & $\begin{array}{l}\text { tilqäizy } \\
\text { spontaneous }\end{array}$ & $\begin{array}{l}-u n \\
-n o m\end{array}$ & $\begin{array}{l}\text { saht } \\
\text { calsy }\end{array}$ & $\begin{array}{l}-u n \\
- \text { nom }\end{array}$ \\
\hline \multicolumn{6}{|c|}{ "An casy, spontaneous success" } \\
\hline $\begin{array}{l}\text { d. najahät } \\
\text { successes }\end{array}$ & $\begin{array}{l}- \text { un } \\
- \text { nomn }\end{array}$ & $\begin{array}{l}\text { kabīrat } \\
\text { hig }\end{array}$ & $\begin{array}{l}\text {-un } \\
\text {-nom }\end{array}$ & & \\
\hline
\end{tabular}

"Big sucesses"

As can be observed, the renderings in (1) constitute communicative equivalents for the English metaphor, that is, the metaphor has been reduced to its communicative import in them. This, it should he noted, is the easiest way of handling a culturally-alien metaphor.

A harder option in the process of translating the foregoing metaphor would involve searching for a functionally-equivalent metaphor in the TL, $i . e$. a cultural substitute (Larson 1984: 170-172). Surprisingly. this option has been only unsuccessfully explored by one examinee. His far-fetched rendering is in (2).

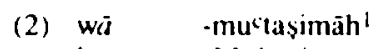

hey -Mu'tasim

"Hey. Mu'tasim! come to my rescue"

As can be seen, the rendering in (2) is completely incongruent with the situation encapsulated in the English metaphor. Interestingly, like the English metaphor, the corresponding Arabic metaphor is religion-based - it makes reference to the opening of the gates to the sky upon which all wishes could be realized. Observe the functional rendering of the sentence containing the foregoing metaphor in (3) below.

(3) lan tanfatiha

will not open

$\begin{array}{ll}\text { abuüh } & -4 \\ \text { doors } & - \text { nom } \\ \text {-jawkat } & -i \\ \text {-round } & \text {-gen } \\ -1 \quad \text {-arabiy' } & \\ \text {-def } & \text {-Arab }\end{array}$

$\begin{array}{ll}-s & -s a m a ̈ \\ - \text { def } & -s k y \\ \min & -a l \\ \text { from } & - \text { def } \\ -i- & -l \\ - \text { gen } & - \text { def }\end{array}$

$\begin{array}{llll}-i & f i & & \\ \text {-gen } & \text { in } & & \\ \text {-hahe } & & -i & \text { 'an -is- } \\ \text {-search } & \text {-gen of } & \text { def- } \\ \text { isrä'ili } & & & \\ \text { Isracli } & & & \end{array}$

"Lit. The gates to the sky will not open in this round of the Arab-Israeli peace search." 
The bulk of the examinees' renderings of the metaphor (9/15), however, represent literal translations that are completely uninterpretable to Arabic native speakers. Apparently, in the heat of attempting to faithfully render the English metaphor by translating it sensu stricto (Broeck 1981: 77), most of the examinees fall in the trap of semanric anomalies. Further, these examinees treat the metaphor as a creative rather than a decorative one, thus their being unaware of the relevance of text-type and, subsequently, the function of the metaphor which is integral to the process of translating. To illustrate, their renderings can be roughly represented in (4).

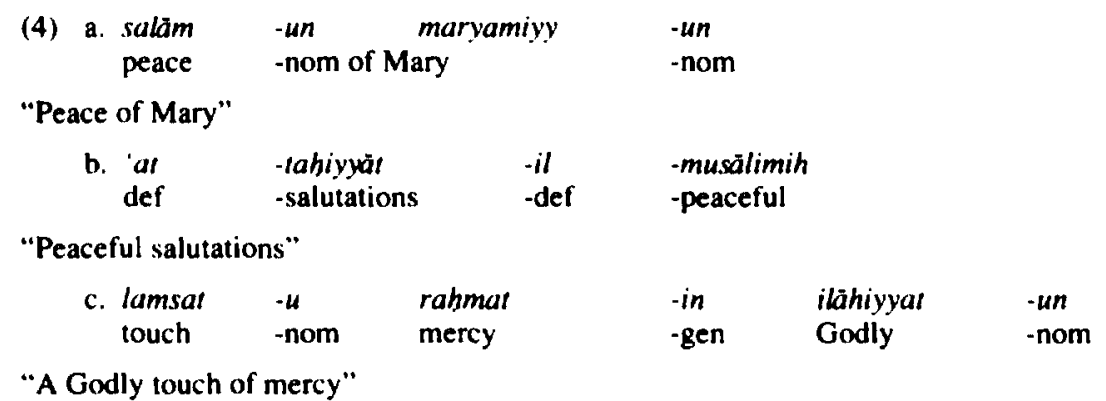

As can be observed, the rendering of (4) derive from the Christian metaphor, hence their being alien to Arabic native speakers. These examinees, most likely, have exclusively relied on bilingual and/or unilingual dictionaries which, in this circumstance, are of little help, for the intended sense is derivable only from the co-text and/or context.

The second study item argued for is an English phrasal verb corresponding, for most native speakers of Arabic, to a lexical gap in Arabic, that is. Arabic lacks a phrasal verb deriving from the Arabic verb / yadala/ argued that corresponds to argued for in English. Consequently, the bulk of the examinees, (12/15), render it communicatively by resorting to cognitive synynoms. Observe the options taken by the examinees which are ordered according to frequency in (5).
(5) a. dacáa 'ilā
b. ayyada
c. waqafa mac
"called for"
d. häe日a cala
"supported"
e. șăqa hujaja
"sided with"
"urged for"
f. ra'a anna
"presented evidence"
"saw that"

Communicatively, the renderings in (5) are working translations of argued for in the text in hand. It should be noted that the option for a cognitive synynom rules out semantic anomaly, for one can't affirm a cognitive synynom while denying the other (for more details, see Cruse 1986: 270-285). Observe the semantic anomaly of the Arabic example along with its English rendering in (6).

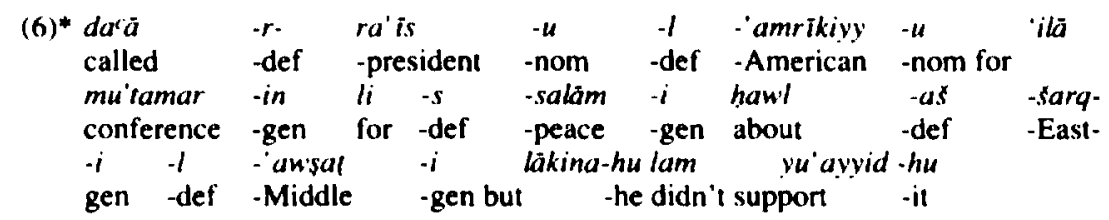

". The American President called for (argued for) a peace conference on the Middle East, but he didn't support it." 
As can be noted. / da'à 'ilä / called for or argued for and / avyada/ supported are cognitive synynoms, hence the semantic anomaly of (6) above.

The examinees' three remaining renderings, being / 'aclana/ announced. / baha $a$ al discussed and / jaddala haw// argued about. are obviously mistranslations. It is worthy of mention that the only attempt to find a formally-and functionally-equivalent Arabic phrasal verb, which, of course, has been unsuccessful, is / jädala hanl/ argued about. despite the fact that, theoretically. Arabic possesses the phrasal verb/ jaidala 'an/ which corresponds both formally and functionally to the English argued for. However, the use of this phrasal verb is virtually confined to Classical Arabic Literature and the Holy Koran.

Unlike the first two study items which create lexical problems relating to the translation of culture-bound metaphors and (seeming) lexical gaps, respectively, the third study item You have to craw/ before you walk, and yeu have to walk before you rum fundamentally creates discoursal problems in the process of translating. To illustrate. the majority of the examinees, $(12 / 15)$, are unaware of the impersonal use of the English personal pronoun you, thus altering it from impersonal to personal one. Their renderings are typically represented in (7).

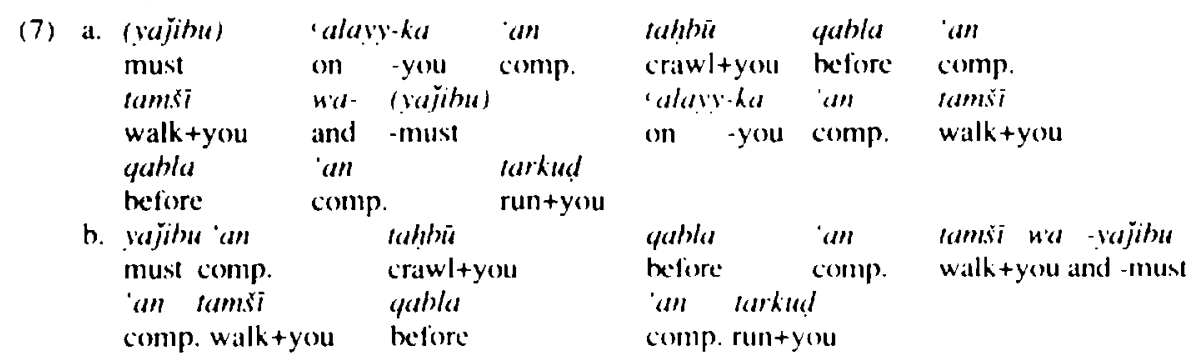

"You (personal) have to crawl before you walk, and you have to walk before you run,"

Obviously, the examinees' option for formal equivalence nullifies the impersonal reading of you in the text. In order to achieve the impersonal reading of you in Arabic, the generic noun $/{ }^{\prime} a l-m a r^{\prime} /\left(o m c^{\prime}\right.$ or $\left.y o u\right)$ should be employed. Thus the functional equivalence for the third study item runs as follows in $(8)$.

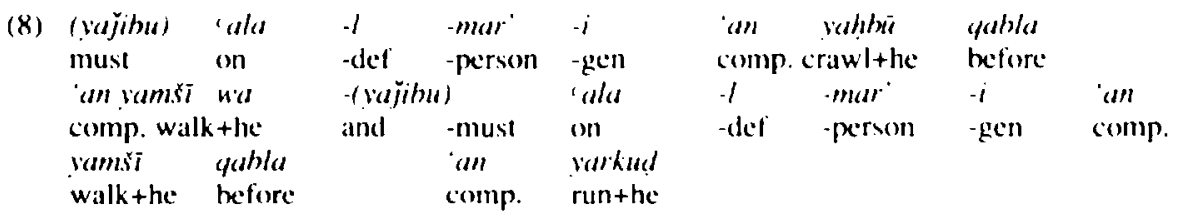

"You have to crawl before you walk, and you have to wall hefore before you run." or

"One has to crawl before he walks, and one has to walk before he runs."

Thus we have, in the above example, a case where grammar interacts with discourse resulting in a discourse-based grammar, viz., the obligatory impersonal reading of you in English text and its corresponding impersonal reading in the TL text. To illustrate, yous is usually assigned the personal reading at the sentence level. Observe the example in (9) along with its Arabic rendering in (10).

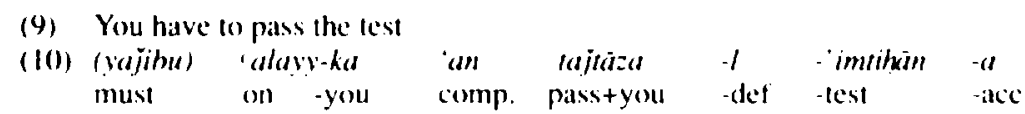


The distinction between (9) and (10), on the one hand, and (8), on the other, is relevant to sentence-meaning as opposed to utterance-meaning.

The fourth study item lean on is an English phrasal verb entered in unilingual and bilingual dictionaries on the market as meaning depend on or rely $o n^{2}$. This dictionary meaning. however, doesn't fit in our text, for the sense of lean on is solely derivable from the co-text, that is, the next sentence in the text which doesn't cohere with the preceding sentence containing lean on if lean on is rendered as depend on. Observe the semantic anomaly of the Arabic rendering in (11) opted for by 12 out of the 15 examinees in this study along with its anomalous English back-translation (for ease exposition, the correct discourse marker / fa-/, which will be discussed in the next section, and its corresponding English marker as have been provided).

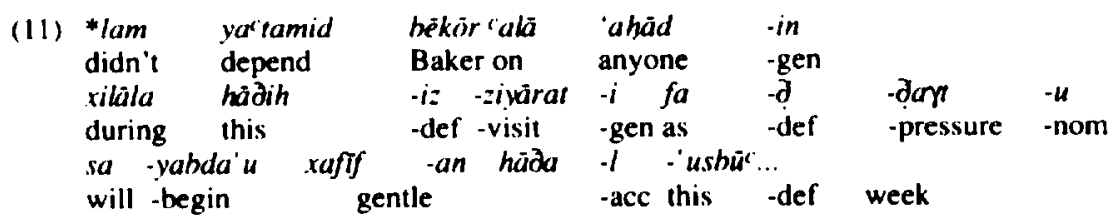

*"Baker didn' $\mathrm{l}$ depend on anyone during this visit, as the pressure will begin gently this week..."

The semantic anomaly in $(11)$ is caused by the non-congruency of / ya'tamid calä/ depend on and /fa- $\partial-\partial a \gamma /-u /$ as the pressure, that is, the resulting pressure can by no means be the consequence of the circumstance of Baker not depending on anyone.

Consequently, the competent translator should rely on his comprehension of the discourse in its entirety in determining the sense of a lexical item rather than on the dictionary meaning on which the majority of the examinees in this study exclusively rely on. Talking about the key role of discourse in working out value of lexical items in the process of translating. Lotfipour-Saedi (1990: 390) writes. "It is the value of the vocabulary items as opposed to their significarion that should be taken into account in determining the TE of SL vocabulary items." Only in this case will the fourth study item be rendered accurately as in (12).

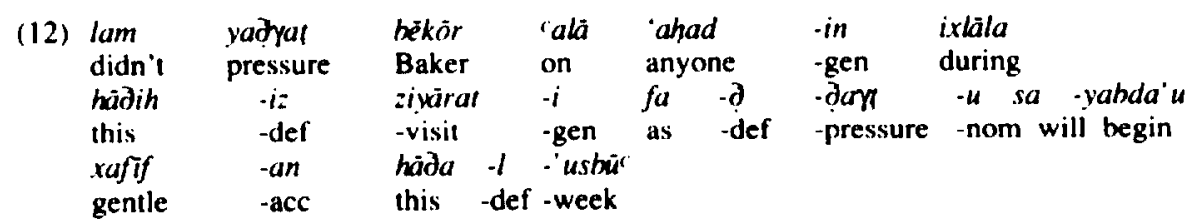

"Baker didn't pressure (lean on) anyone during this visit, (as) the pressure will begin gently this week..."

By far, the discussion implies that Arabic is only in possession of a communicative equivalent to lean on, that is / yaḑya! calä/. This, however, is not the case, for Arabic possesses the phrasal verb / yamil cala / as both formally and functionally equivalent to lean on. Therefore, the competent translator has, in fact, two options available to him: either to seek communicative equivalence, thus minimally altering the cognitive effect on the SL

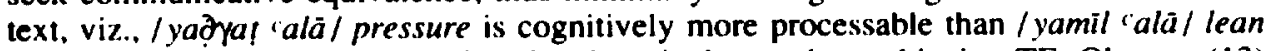
on, or to seek both formal and functional equivalence, thus achieving TE. Observe (13) below which exhibits both formal and functional equivalence, other things being equal, to the sentences in the SL text. 


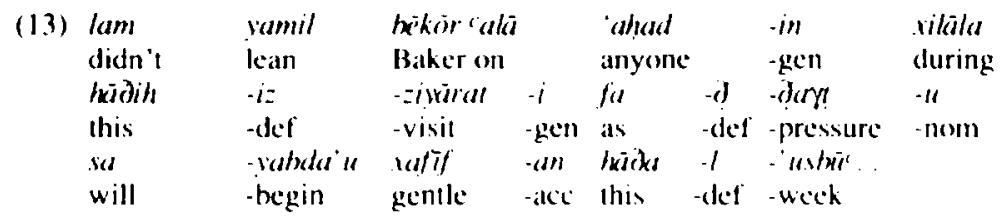

"Baker didn't lean on anyone during this visit. The pressure will gently begin this week..."

Unfortunately, the first option is explored by only two of the examinees, while the second enjoys no luck et all.

Finally, the fifth study item. which is indicated by a zero-marker in the SI. text, is purely discoursal. In English, the writer has two textualizations available to him: either to implicitly mark the thought-relationship between the two sentences (the writer of the SL. text has taken this option) or to explicitly mark this thought-relationship, the discourse marker as is a good candidate. Observe the explicitly marked thought-relationship in (14) below.

(14) Baker didn't lean on anyone during this visit. as the pressure will begin gently this week...

As for Arabic, the discourse marker / fa- / is obligatory rather than optional, i.e.. in order to provide textual cohesion, the translator has only one textualization available to him when translating this segment of the SI. text into Arabic (sec ex. (12) and (13) above). Therefore, the most important lask of the translator is to work out what kind of thought-relationship exists between the two sentences, $i . e^{\prime}$. whether it is an addition relationship, a contrast relationship, or a cause-elfect relationship. In the SI. text, it turns out to be a circumstantional cause-effect relationship, hence the choice of the Arabic discourse marker / $f(a-/$. The failure to work out the thought-relationship holding between the two sentences would result in a break-down in communication. Infortunately, this happens with 13 out of the 15 examinees in this study: 7 construe it as an addition thoughtrelationship, while 6 construe it as a contrast thought-relationship. Thus two examinees only manage to work out the correct thought-relationship. This points to at major comprehension problem on the part of the examinees. Necedless to say, comprehension constitutes a pre-requisite for being engaged in any Iranslation task, let alone, among other things, the lexical and discoursal problems we have been worrying about in this paper.

\section{CONCLUSION}

The present paper has brought to spotlight five lexical and/or discoursal problems in English-Arabic translation. It has been demonstrated that the search for TE involves, among other things, many lexical and discoursal decisions on the part of the competent translator. The translator's inability to cope with lexical and discoursal problems arising at some junctures in the process of translating would undoubtedly mitigate the effectiveness of his translation within a scope ranging from minimal loss of Tl: e.g. the choice

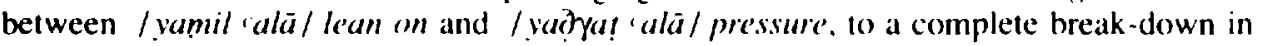
communication. e.g. the replacement of a cause-effect thought-relationship in the SL. text by a contrast thought-relationship in the TL. text. This being so, student translators as well as translation practioners should the sensitized to the subtleties of lexis and discourse, and the resulting interaction between them, in the process of translating.

Of particular interest to translation theorists is the unjustified over-dependence of student Iranslators, and probably translation practioners, on dictionaries. whether they be unilingual or hilingual. In the best of worlds, this over-dependence could bring forth 
unnatural or awkward translations. Normally, however, this practice creates incoherence in the TL text. thus leading to a break-down in communication at some points. This being the case, student translators as well as translation practioners should be encouraged to discoursally work out the value of lexical items, thus minimizing the use of dictionaries in the process of translating.

Finally, this study has explicitly demonstrated that the SL text must be subjected to extensive intrinsic managing (Farghal 199lb) in the process of re-encoding it in the TL. This ranges from managing individual lexical entities to managing entire textualizations. At one end of the continuum, it has been shown how the English metaphor Hail Mary passes should be intrinsically managed by either reducing it to its communicative sense or by replacing it by a cultural substitute. At the other end of the continuum, it has been demonstrated how an implicit textualization in the SL text must be rendered an explicit one in the TL text. Consequently, the translator's awareness of the inevitableness of intrinsic managing in the process of translating highly contributes to bringing forth natural/idiomatic translations that would bring them nearer to the equivalent effect principle.

Notes

1. This was a call for help directed at Al-Mu'tasim, an Abbasid Calif, by an Arab woman upon the Byzantines' storming of 'Amuriyyah' fortress in Northern Syria in the 9th century.

2. The one exception to this is Collins Cobuild Dictionary of the English Language (Birmingham University Intemational Database) which lists pressuriz' as the firsi meaning of the English phrasal verb fean on.

\section{REFERENCES}

BOL.JNGER, D. (1966) : "Transformulation: Structural Translation", Acta Linguistical Hafniensia. 1X. pp. 130-144. BROECK, R. (1981): "The Limits of Translatability Exemplified by Metaphor Translation". Poetics Todoy. 2-4. Pp. 7.3-87.

CATFORD. J. (196.5) : A Linguistic Theory of Translation. London, Oxford University Press.

CRUSE, D. (1986) : Lexwal Semuntic:s, Cambridge University Press.

DAGUT, M. (1981) : "Semantic 'Voids' As a Problem in the Translation Process". Poetics Todday. 2-4. pp. 61-71.

FARGHAL. M. (1991a): "Evaluativeness Parameler and the Translator from English into Arabic and Vice Versa". (o) appear in Bahel.

FARGHAL, M. 11992,: "Managing in Translation: A Theoretical Model". Melu, 38.2, Montreal, Presses du l'Université de Montréal. pp. 257-267.

GARCIA-LANDA. M. (1981): "A General Theory of Translation (and of Language)", Meta. 35-3, Montreal, Presses de l'Université de Montréal, pp. 476-487.

IVIR, V. (19K1) : "Formal Correspondence vs. Translation Equivalence Revisited", Psesics Today, 2-4, pp. 51-59.

JAKOBSON, R. (1959) : "On Linguistic Aspects of Translation". R. Brower (Ed.). On Trans/arion, Harvard University Press, pp. 232-239.

KACHRU, Y. (1982) : "Towards Defining the Notion 'Fquivalence' in Contrastive Analysis". TE.SL5. University of Illinois at Urbana-Champain. pp. 82-98.

KRZESZOWSKI, T. (|97|): "Equivalence, Congruence and Deep Structure". G. Nickel (Ed.), Papers in Confrastive Linguisfics. Cambridge University Press, pp. 37-48.

LARSON, M. (1984): Meaning-hased Translation. Pergamon Press.

LOTFIPOUR-SAEDI, K. ( 1990$)$ : "Discourse Analysis and the Problem of Translation Equivalence". Meta. 35-2. pp. 289-297.

NEWMARK, P. (1981) : Approaches so Transiation, University Press of America.

NEWMARK. P. (I98X) : A Tewhook of Translation. Prentice Hall International (UK) Ltd.

NIDA. E. (1964): Tonard a Sicience of Translating, Leiden, Brill.

NIDA, E. (1969) : "Science of Translation". Laneuage, 45, pp. 483-498.

NIDA. E. (1977): "The Nature of Dynamic Equivalence in Translating", Babel, 23, pp. 99-103.

WAARD. J. de and E. NIDA (1986): From One Language (o Another: Functonal Equivalence in Bible Translating. Thomas Nelson Publishers. 